\title{
PRODUÇÃO RECOMBINANTE DA ENZIMA LIGNINA PEROXIDASE DE Lentinus tigrinus EM CÉLULAS DE Escherichia coli.
}

\author{
Cleidineia Souza de Santana ${ }^{1}$; Hélio Mitoshi Kamida ${ }^{2}$; Raquel Guimarães Benevides ${ }^{3}$ \\ 1. Bolsista PIBIC - Af/CNPq, Graduando em Bacharelado em Ciências Biológicas, Universidade Estadual de Feira de \\ Santana, e-mail: s.santanacleide@yahoo.com.br \\ 2. Orientador, Departamento de Ciências Biológicas, Universidade Estadual de Feira de Santana, e-mail: \\ hmkamida72@gmail.com \\ 3. Participante do projeto, Departamento de Ciências Biológicas, Universidade Estadual de Feira de Santana, e-mail: \\ raquelgb@gmail.com
}

PALAVRAS CHAVES: fungo; resíduos agroindustriais; enzima.

\section{INTRODUÇÃO}

O Brasil é o maior produtor mundial de açúcar e etanol; de acordo com dados de 2017 da União da Indústria de Cana-de-açúcar (UNICA), entre 2016 e 2017, aproximadamente 652 mil toneladas de cana de açúcar foram comprimidas e 27,2 milhões de metros cúbicos de etanol foram produzidos, gerando uma grande quantidade de bagaço de cana.

A acumulação de resíduos agroindustriais devido às altas taxas de produção, muitas vezes, pode causar vários problemas de gerenciamento e eliminação. Existem muitos casos em que os resíduos agroindustriais têm sido indevidamente descartados, ou depositados em aterros, acarretando danos ambientais (Pellera, 2016).

Materiais lignocélulosicos são fontes abundantes de compostos orgânicos, apresentando grande potencial de uso como matéria prima em processos industriais para produção de alimentos, combustíveis, insumos químicos, enzimas e bens de consumo diversos (Latif; Rajoca, 2001). Uma grande variedade de fungos e bactérias consegue degradar esse material lignocelulósico usando uma bateria de enzinas hidrolíticas e oxidativas (Vitti, 1988).

Desse modo, o presente trabalho propõe avaliar a expressão da enzima Lignina peroxidase (LiP) do fungo Lentinus tigrinus e sua clonagem em células de E. coli objetivando-se uma futura aplicação na deslignificação no bagaço de cana.

\section{METODOLOGIA}

A linhagem de Lentinus tigrinus (CCMB552), foi adquirida na Coleção de Cultura de Microrganismos da Bahia (CCMB) da UEFS, preservado em método Castellani. Para a reativação do fungo o micélio de Lentinus tigrinus foi transferido para meio de cultura sólido, Agar batata e dextrose (BDA) e posteriormente o micélio foi transferido para o meio de cultura semissólido, bagaço de cana e sulfato de amônia (BCSA), utilizando-se as seguintes concentrações ( $8 \mathrm{~g}$ de Ágar, $8 \mathrm{~g}$ de bagaço de cana, $2 \mathrm{~g}$ de sulfato de amônia e $400 \mathrm{ml}$ de água destilada) sendo incubado em B.O.D a $25^{\circ} \mathrm{C}$ por 5 dias, para induzir a produção da enzima de interesse.

No procedimento de extração de RNA, seguiu-se o protocolo do Reagente Trizol (Invitrogen $囚$ ). Para o processo de extração fez-se a remoção do fungo da placa de petri, transferindo-o para o cadinho e macerado em nitrogênio liquido, após o fungo ser totalmente macerado foi transferido para um microtubo de $2 \mathrm{~mL}$, em seguida adicionou-se $1 \mathrm{~mL}$ do reagente Trizol e foi homogeneizado em vórtex por aproximadamente 5 segundos; após homogeneizado a mistura foi incubada em gelo por 5 minutos. Decorridos os cinco minutos fez-se o procedimento para a separação das fases, adicionou-se $200 \mu \mathrm{L}$ de clorofórmio e em seguida agitou-se manualmente por 15 segundos, depois foi incubado por 3 minutos em gelo, seguindo-se, foi centrifugado a $12.000 \mathrm{xg}$, por 10 minutos a $4^{\circ} \mathrm{C}$. Depois de centrifugada houve a formação de 3 fases, sendo estas: clorofórmio-fenol, interfase e a fase aquosa, esta foi transferida para um novo microtubo. Após a separação das fases, fez-se o isolamento do 
RNA; nesse processo adicionou-se $500 \mu \mathrm{L}$ de isopropanol $100 \%$ à fase aquosa e em seguida foi incubado em gelo por 10 minutos, após isso centrifugou-se a 12.000xg por 10 minutos a $4^{\circ} \mathrm{C}$, prosseguindo-se, foi retirado o sobrenadante e o pellet foi lavado com $1 \mathrm{ml}$ de etanol $75 \%$, agitou-se em vórtex, em seguida centrifugou-se novamente a 7500x $g$ por 5 minutos a $4^{\circ} \mathrm{C}$, descartou-se o sobrenadante e deixou-se o pellet secar por até 10 minutos.

Transcorridos esse tempo o RNA foi ressuspendido em $50 \mu \mathrm{L}$ de água RNAse-free, o RNA obtido foi armazenado em $-20^{\circ} \mathrm{C}$. O RNA extraído foi analisado quantitativamente pela técnica de espectofotometria, sendo também analisado por visualização em fotografia digital, após 1 hora de corrida eletroforética. Posteriormente foi feita a síntese de DNA complementar utilizando-se a enzima M-MLV Reverse Transcriptase, seguindo-se as recomendações do fabricante.

Os primers para o gene da enzima em estudo Lignina peroxidase foram desenhados com base nas sequências nucleotídicas disponíveis no banco de dados NCBI - (National Center for Biotechnology Information) https://www.ncbi.nlm.nih.gov/nucleotide/. A verificação da estrutura do primer, porcentagem de conteúdo $\mathrm{C} / \mathrm{G}$, bem como temperatura de melting $(\mathrm{Tm})$, foi feita utilizando o simulador gratuito de construção de primer disponível na página https://www.idtdna.com/calc/analyzer.

A amplificação do cDNA foi feita por meio da reação de polimerização em cadeia (PCR). Como fita molde foi utilizada a primeira fita de cDNA e como iniciadores, o primer para o gene (como senso) e oligo-dT (Ancor Primer, anti-senso). A reação foi feita utilizandose o kit Quiagen ${ }^{\circledR}$ Master Mix: enzima Top taq Master mix, iniciadores para o gene ( primers senso e anti-senso), DNA como molde e Agua Nucleasefree, as condições para a reação de PCR foi feita de acordo com as instrução do fabricante, seguindo-se as etapas da tabela 2.

Tabela 1 - Etapas referentes à reação de polimerase em cadeia

\begin{tabular}{llll}
\hline PASSO & $\begin{array}{l}\text { TEMPERATUR } \\
\text { A }\left({ }^{\circ} \mathbf{C}\right)\end{array}$ & TEMPO & $\mathbf{N}^{\circ}$ CICLOS \\
\hline $\begin{array}{l}\text { Desnaturação } \\
\text { Inicial }\end{array}$ & 94 & $3^{\prime}$ & 1 \\
Desnaturação & 94 & $45^{\prime}$, & 35 \\
Anelamento & 59 & $1^{\prime}$ & 35 \\
Extensão & 72 & $3^{\prime}$ & 35 \\
Extensão Final & 72 & $5^{\prime}$ & 1 \\
\hline
\end{tabular}

O produto obtido a partir da reação de PCR foi purificado utilizando-se o kit PureLink ${ }^{\circledR}$ Quick Gel Extraction - o procedimento foi feito seguindo as recomendações do fabricante.

\section{RESULTADOS E DISCUSSÃO}

O fungo cultivado em meio BDA, por 5 dias, a $25^{\circ} \mathrm{C}$, apresentou elevada produção de biomassa considerado ótimo para o crescimento do fungo e para o seu desenvolvimento em termos de produção de biomassa micelial, tal crescimento é devido ao fato do meio BDA ser rico em nutrientes, não sendo viável em termos de verificação de atividade enzimática para a enzima de interesse haja vista que trata-se de um meio ausente de materiais ligninocelulósicos, não configura um potencial indutor da expressão da enzima, porém, além dos nutrientes contém valores significativos de açúcar, sendo avaliado como um meio ótimo para reativação, indicado por favorecer o crescimento micelial fúngico.

Quando submetido à extração de RNA total o fungo Lentinus tigrinus cultivado em meio semissólido BCSA, após a análise quantitativa, obteve-se concentrações entre 4 e 6 $\mu \mathrm{g} / \mu \mathrm{L}$, apresentando relações de absorbância entre 1,7 e 2,0 para a razão A260/280. Esses 
valores fornecem uma estimativa da pureza dos ácidos nucleicos em relação à contaminação com fenol ou proteínas (Regitano, 2007), sendo possível verificar a integridade do RNA extraído, tendo em vista que as bandas referentes aos RNAr $28 \mathrm{~S}$ e $18 \mathrm{~S}$ mostram-se detectáveis após a visualização em eletroforese em gel de agarose a 1\% (Figura 1).

O primer desenhado para a sequência codificante da proteína (tabela 2) em estudo apresentou resultado positivo para a amplificação do fragmento desejado quando otimizada a temperatura de anelamento, de $65,6^{\circ} \mathrm{C}$ para $59^{\circ} \mathrm{C}$. Esse resultado pode estar relacionado ao fato de que temperaturas muito altas ou próximas a temperatura de extensão podem impedir o pareamento do primer com a região específica.

Tabela 2: Dados referentes ao primer desenhado

\begin{tabular}{cccc} 
Denominação & Sequência $\left(\mathbf{5}^{\prime} \mathbf{3}^{\prime}\right)$ & $\begin{array}{c}\text { Teor de } \\
\mathbf{C} / \mathbf{G}\end{array}$ & $\begin{array}{c}\text { Temp. de } \\
\text { melting } \\
(\mathbf{T m})\end{array}$ \\
\hline LiP_2 & ACT GCN TGY GAG TGG CAG TCG & $56,2 \%$ & $65,6^{\circ} \mathrm{C}$ \\
\hline
\end{tabular}

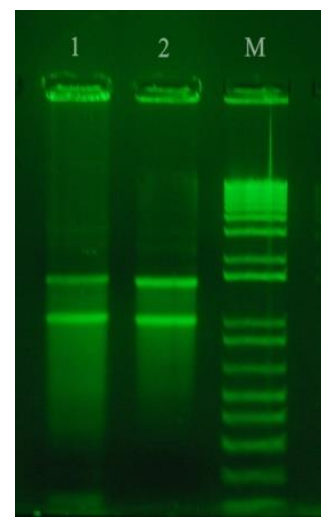

Figura 1: Gel de agarose 1\% com resultado de RNA cultivado em BCSA. Da direita para a esquerda: M: Marcador de massa molecular de 1kb, plus DNA Ladder Invitrogen; 1 e 2: RNA de Lentinus tigrinus.

O resultado da amplificação relativa à sequência codificante de LiP de Lentinus tigrinus, com o uso do primer específico desenhado, após a reação de PCR, com a utilização do cDNA obtido à partir da extração de RNA, foi verificado por eletroforese em gel de agarose $1 \%$, onde foi possível constatar a amplificação do fragmento esperado de aproximadamente $650 \mathrm{pb}$. (Figura 2).

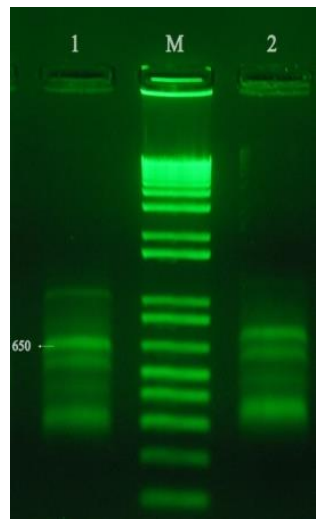

Figura 2: Gel de agarose $1 \%$ com resultado do PCR a partir do cNDA de Lentinus tigrinus cultivado em meio BCSA. M: Marcador de massa molecular de 1kb, plus DNA Ladder Invitrogen - Invitrogen; 1 e 2: Amplificados referente à sequencia. 
A presença do fragmento em torno de $650 \mathrm{pb}$, do tamanho esperado em relação às sequências de referência utilizadas para desenhar o primer específico, confirma a expressão do RNAm referente à sequência codificante de LiP em Lentinus tigrinus.

Os resultados para enzimas ligninocelulósicas provindos da utilização do bagaço de cana, corrobora com alguns autores, como, Menezes et al. (2009) ao avaliar a produção de enzimas ligninolíticas (lacase e manganês peroxidase) pelos fungos do gênero Pleurotus $(P$. $s p$ BCCB068, P. tailândia e $P$. sajor-caju), e Silva et al. (2014), ao cultivar o fungo Trametes villosa (Sw.) Kreisel através do uso do bagaço de cana-de-açúcar, constatando a produção da enzima manganês peroxidase (MnP).

Segundo os referidos autores, resíduos agroindustriais a exemplo do bagaço de cana é um substrato com alta capacidade de induzir a produção de enzimas ligninolíticas pelos fungos basidiomicetos.

\section{CONSIDERAÇÕES FINAIS}

A partir dos resultados por meio da extração de RNA, pode-se concluir que o meio BCSA foi favorável para a expressão da enzima Lignina peroxidase pelo fungo Lentinus tigrinus. Com base no produto de L. tigrinus, após a reação de PCR dos produtos de cDNA, foi possível verificar o fragmento de $650 \mathrm{pb}$ referente à amplificação da região específica de LiP, confirmando que houve a indução da enzima Lignina peroxidase.

\section{REFERÊNCIAS}

LATIF, F.; RAJOCA, M. I. Production of etanol and xylitol fromcornocobsby yeasts. Bioresearch Tecnology, Essex, v. 77, p. 57-63, 2001.

MENEZES, C. R.; SILVA, I. S.; DURRANT, L. R. Bagaço de cana: fonte de produção de enzimas lignocelulolíticas. Estudos tecnológicos. vol. 5, n. 1. p. 68-78, 2009.

PELLERA, Frantseska-Maria; GIDARAKOS, Evangelos. Effect of substrate to inoculum ratio and inoculum type on the biochemical methane potential of solid agroindustrial waste. Journal of Environmental Chemical Engineering, v. 4, n. 3, p. 3217-3229, 2016.

REGITANO, L. C. de A.; NICIURA, S. C. M.; IBELli, A. M. G.; GOUVEIA, J. J. de S. Protocolos em biologia molecular aplicada à produção animal. São Carlos: Embrapa Pecuária Sudeste. 2007..

SILVA, M. L. C. ET AL. Production of manganese peroxidase by Trametes villosa on unexpensive substrate and its application in the removal of lignin from agricultural wastes. Advances in Bioscience and Biotechnology. v. 5, n. 14, p. 1067. 2014.

THIRIBHUVANAMALA, G., KALAISELVI, G., PARTHASARATHY, S., \& ANUSHA, B. Induction of lignolytic enzyme activities in different agro residues by the white rot fungi, Pleurotus sajar-caju. International Journal of Chemical Studies. v. 5, n. 2, 89-94. 2017.

VITTI, L. S. S. Condições de produção e atividade da celulose do fungo Aspergillus sp e seus mutantes isolados de bagaço de cana. 1988. 108 p. Dissertação (Mestrado em Energia Nuclear na Agricultura) - Centro de Energia Nuclear na Agricultura, Universidade de são Paulo, Piracicaba, 1988. 